Abstract P248 Table 1 Results for all IPF patients: Demographics and Disease Severity by FVC percent predicted

\begin{tabular}{|c|c|c|c|c|c|}
\hline \multicolumn{6}{|l|}{ Total IPF patients $n=528$} \\
\hline \multicolumn{3}{|l|}{ Sex } & Male & Female & Row total \\
\hline \multicolumn{3}{|l|}{ Number of patients (proportion) } & $431(82 \%)$ & $97(18 \%)$ & 528 \\
\hline \multicolumn{3}{|l|}{ Ethnicity } & Caucasian & \multicolumn{2}{|l|}{ Non-Caucasian } \\
\hline \multicolumn{3}{|l|}{ Number of patients (proportion) } & $453(86 \%)$ & $75(14 \%)$ & 528 \\
\hline & Characteristic & Unit & Median & \multicolumn{2}{|l|}{ IQ range } \\
\hline & Age & years & 72 & \multicolumn{2}{|l|}{$68-78$} \\
\hline & FVC & litres & 2.175 & \multicolumn{2}{|l|}{$1.700-2.780$} \\
\hline \multirow[t]{5}{*}{ Reference equations used } & ECSC & FVC\%pred & 64.9 & \multicolumn{2}{|l|}{$52.2-75.9$} \\
\hline & GLI & FVC\%pred & 60.6 & \multicolumn{2}{|l|}{$49.3-72.4$} \\
\hline & NHANES & FVC\%pred & 58.9 & \multicolumn{2}{|l|}{$49.4-70.0$} \\
\hline & & & \multicolumn{3}{|c|}{ FVC percent predicted range } \\
\hline & & & $>80 \%$ & $<80 \%$ & Row total \\
\hline \multirow[t]{3}{*}{ Reference equations used } & ECSC & Number of patients & 98 & 430 & 528 \\
\hline & GLI & & 73 & 455 & 528 \\
\hline & NHANES & & 64 & 464 & 528 \\
\hline
\end{tabular}

percent predicted; $\mathrm{IQ}=$ interquartile

function reports. Those choosing reference values must be aware of implications for patients.

\section{P249 COMPARISON OF PHYSIOLOGICAL VERSUS MATHEMATICAL METHODS FOR QUALITY CONTROL IN MBW NORMALISED PHASE III ANALYSIS}

${ }^{1} \mathrm{M}$ Arigliani, ${ }^{2} \mathrm{~N}$ Verger, ${ }^{3} \mathrm{E}$ Raywood, ${ }^{3} \mathrm{~J}$ Duncan, ${ }^{4} \mathrm{~A}$ Bush, ${ }^{5} \mathrm{P}$ Aurora on behalf of the London Cystic Fibrosis Collaboration. 'Department of Clinical and Experimental Medical Sciences, Unit of Paediatrics, University Hospital of Udine, Udine, Italy; ${ }^{2}$ Université Pierre et Marie Curie, Paris, France; ${ }^{3}$ Respiratory, Critical Care and Anaesthesia Section, IIIP, UCL Institute of Child Health, London, UK; ${ }^{4}$ The National Heart and Lung Institute, Imperial College, London, UK; ${ }^{5}$ Department of Respiratory Medicine, Great Ormond Street Hospital for Children, London, UK

\subsection{6/thoraxjnl-2016-209333.392}

Background Breathing pattern cannot be controlled in small children, so multiple breath washout SnIII analysis has to exclude inadequate volume breaths.

Aim To compare an existing mathematical breath exclusion algorithm with a physiological method.

Methods School age children with CF (30) and controls (30) performed SF6MBW with mass spectrometer, with uncontrolled tidal breathing. Two different breath exclusion methods were compared, with exclusion based on:

1) Expired tidal volume (VT) deviating by $>25 \%$ of the median $\mathrm{VT}^{1}$

2) VT $<3$ Langley dead space ${ }^{2}$ volume or $90 \%$ bigger than the median VT

Runs with $>33 \%$ excluded breaths were removed. Volume corrected Scond was calculated from subjects with 3 valid runs.

Results Far fewer subjects were excluded by the physiological Langley method, than by the mathematical method (Table). The mean and SD for Scond was identical by both methods, implying that the mathematical algorithm excludes valid data.

Abstrct P249 Table 1
\begin{tabular}{|l|c|c|c|}
\hline & \multicolumn{2}{|c|}{ Breath size exclusion criteria } & Mean diff (95\% Cl) \\
\hline & $\mathrm{VT} \pm 25 \%$ & $\begin{array}{c}\text { Langley } \\
\text { correction }\end{array}$ & \\
\hline Number of subjects excluded & $30 / 60$ & $12 / 60$ & \\
\hline $\mathrm{S}_{\text {cond }}(\mathrm{SD})$ controls & $0.009(0.012)$ & $0.011(0.012)$ & $-0.011 ; 0.006$ \\
\hline $\mathrm{S}_{\text {cond }}(\mathrm{SD}) \mathrm{CF}$ & $0.070(0.025)$ & $0.072(0.025)$ & $-0.004 ; 0.0009$ \\
\hline
\end{tabular}

Conclusion A physiological approach to data cleaning prior to SnIII analysis allows retention of data that would be inappropriately excluded mathematically.

\section{REFERENCES}

1 Bigler A, et al. Paediatric Pulmonol 2015;50(8):805-13.

2 Langley FE, et al. Colloques INSERM 1975;51:209-212.

\section{P250 REAL FLIGHT SPO2 COMPARES WITH HYPOXIC CHALLENGE TESTING IN ADULTS WITH CYSTIC FIBROSIS}

R Peat, J Furlong, E Spencer, D Russell, M Ledson, MJ Walshaw. Liverpool Heart and Chest Hospital, Liverpool, UK

\subsection{6/thoraxjnl-2016-209333.393}

Introduction Limited data are available comparing air travel with the hypoxic challenge test (HCT) in adults with cystic fibrosis (CF). The aim of this study was to assess the predictive capability the HCT to in-flight hypoxaemia in adult passengers with CF.

Methods Fifteen subjects (three male) volunteered for this study. Lung function measurements (FEV1) were performed pre and post flight. Oxygen saturation measured by pulse oximetry (SpO2) and symptoms were recorded in-flight on both outward and inward flights. The HCT was performed post flight and the in-flight oxygenation response was compared to the HCT and lung function results. 
Results All subjects flew without the use of oxygen, and no adverse events were recorded in-flight. Air travel caused significant desaturation $\left(\mathrm{p}<0.001\right.$ ) (mean pre flight $\mathrm{SpO}_{2} 95+-1 \%$; mean in-flight $\mathrm{SpO}_{2} 90 \pm 3 \%$ ). The HCT caused mean desaturation $(\mathrm{p} \leq 0.001)$ that was comparable to that of air travel $(90 \pm$ $3 \%)$. The pre flight FEV1 and in-flight $\mathrm{SpO}_{2}$ showed weak correlation $(\mathrm{r}=0.41 \mathrm{p}=0.125)$. The $\mathrm{HCT} \mathrm{SpO}_{2}$ showed strong correlation with in-flight $\mathrm{SpO}_{2}(\mathrm{r}=0.74 \mathrm{p}<0.001)$. The HCT showed the strongest correlation with the lower $\mathrm{SpO}_{2}$ value measured from both outward and inward flights $(\mathrm{r}=0.92$ $\mathrm{p}<0.001)$.

Conclusions Significant in-flight desaturation can be expected in passengers with CF. The HCT results compare favourably with air travel data and may be considered the best widely available laboratory test to predict in-flight hypoxaemia in adults with CF.

\section{P251 DOES FRACTIONAL EXHALE NITRIC OXIDE AND METHACHOLINE CHALLENGE TEST HELP IN THE DIAGNOSIS OF AIRWAYS DISEASE?}

IJ Cliff, M Hepple, MB Allen. Royal Stoke University Hospital, Stoke-on-Trent, UK

\subsection{6/thoraxjnl-2016-209333.394}

Introduction With proposed NICE changes to the diagnosis of asthma, ${ }^{1}$ which recommend the use of fractional exhale nitric oxide (FeNO) at a positive value of $\geq 35 \mathrm{ppb}$ and a change in direct challenge test (Methacholine) from 16 to $8 \mathrm{mg} / \mathrm{ml}$ as a cut off for positive responses, we have reviewed our data to assess the impact of these changes.

Methods A retrospective review of results from 2009 to 2016 where methacholine challenge tests (MCT) and FeNO were performed simultaneously in patients with normal spirometry in the assessment of airways disease.

Results Results were available on 145 patients and are tabulated below for both the cut off for $\mathrm{MCH}$ of $16 \mathrm{mg} / \mathrm{ml}$ (current) ${ }^{2}$ and the new cut off value of $8 \mathrm{mg} / \mathrm{ml}$.

Conclusions Altering the threshold for MCT produces 10 less positive results (7\%) reducing the clinical assumption of airways disease. Likewise, 17 had a positive FeNO and a negative challenge test irrespective of the MCT threshold. However, adopting this change reduced the number of negative FeNO and positive MCT from 32 to 22.

In our population, patients referred for a diagnosis of airways disease with normal spirometry showed a large number of patients were both negative for FeNO and MCT and changing the MCT threshold does not significantly impact our group.

\begin{tabular}{lll} 
Abstract P251 Table 1 & \\
\hline & FeNO +ve & FeNO - ve \\
PC20 +ve $(\leq 16 \mathrm{ml} / \mathrm{mg})$ & 6 & 32 \\
PC20 - ve $(>16 \mathrm{ml} / \mathrm{mg})$ & 17 & 90 \\
Pearson Chi-Square $=0.000$, DF $=1, \mathrm{P}=$ Value $=0.989$ & \\
PC20 +ve $(\leq 8 \mathrm{~m} / \mathrm{mg})$ & 6 & 22 \\
PC20 - ve $(>8 \mathrm{ml} / \mathrm{mg})$ & 17 & 100 \\
\hline
\end{tabular}

Pearson Chi-Square $=0.806, \mathrm{DF}=1, \mathrm{P}=$ Value $=0.369$

\section{REFERENCES}

1 NICE. Asthma: diagnosis and monitoring of asthma in adults, children and young people. Draft for Consultation. https://www.nice.org.uk/guidance/gid-cgwave0640/ resources/asthma-diagnosis-and-monitoring-draft-guideline2 2015 (accessed 30 June 2016).

2 Crapo $R$, et al. Guidelines for methacholine and exercise challenge testing-1999, This official statement of the American Thoracic Society was adopted by the ATS Board of Directors, July 1999. AJRCCM 2000;161(1):309.

\section{P252 ACCURATE MEASUREMENT OF LUNG FUNCTION IN THE WORKPLACE AND POTENTIAL EFFECTS OF UNDERESTIMATION}

${ }^{1} \mathrm{JE}$ Sumner, ${ }^{1} \mathrm{E}$ Robinson, ${ }^{1} \mathrm{~A}$ Codling, ${ }^{2} \mathrm{~L}$ Lewis, ${ }^{1} \mathrm{RE}$ Wiggans, 'LM Bradshaw, ${ }^{1} \mathrm{CM}$ Barber, ${ }^{1} \mathrm{~N}$ Warren, ${ }^{3} \mathrm{~S}$ Forman, ${ }^{1} \mathrm{D}$ Fishwick. 'Centre for Workplace Health, HSE, Buxton, UK; ${ }^{2}$ Sheffield Teaching Hospitals, Sheffield, UK; ${ }^{3} \mathrm{CMU}$, HSE, Bootle, UK

\subsection{6/thoraxjnl-2016-209333.395}

Introduction Accurate workplace spirometry measurement is key to giving workers the best clinical assessment of their respiratory health. We were interested in the underestimation of spirometry that occurs if best practice is not adhered to and the significance of this on assessment of health at work.

Methods 667 stone, brick and foundry workers (with varying spirometry experience), carried out lung function testing as part of a larger cross sectional workplace study. Each performed a minimum of 3 forced expirations. Testing continued until each worker had met the ATS/ERS guidance. The final $\mathrm{FEV}_{1}$ and FVC recorded was the maximum value attained from 3 technically acceptable blows, and that the two highest $\mathrm{FEV}_{1}$ and FVC values were within $150 \mathrm{mls}$. Using the final $\mathrm{FEV}_{1}$ and $\mathrm{FVC}$ for each worker, it was then possible to calculate the underestimate of both measures, had only the first blow, or the maximum of the first two blows, been used for interpretation.

Results 613 of the 669 (91.6\%) attained the ATS/ERS criteria based on $\mathrm{FEV}_{1}$. Analysis of the first actual blow, regardless of technical quality, showed an $\mathrm{FEV}_{1}$ mean underestimate of 250 $\mathrm{mls}($ median $=80 \mathrm{mls}, \mathrm{IQR}=210 \mathrm{mls}$ ). If only the first technically acceptable blow had been carried out, the $\mathrm{FEV}_{1}$ would have been underestimated by a mean of $114 \mathrm{mls}(60 \mathrm{mls}, 150 \mathrm{mls})$. If only two technically acceptable blows had been carried out, and the maximum of these used, the $\mathrm{FEV}_{1}$ would have been underestimated by a mean of $36 \mathrm{mls}(0 \mathrm{mls}, 50 \mathrm{mls})$. Similarly, the FVC would have been underestimated by a mean of $131 \mathrm{mls}(75 \mathrm{mls}$, $180 \mathrm{mls}$ ) if only the first technically acceptable blow had been used for interpretation. If only two technically acceptable blows were carried out, the FVC would have been underestimated by a mean of $43 \mathrm{mls}$ ( $0 \mathrm{mls}, 50 \mathrm{mls}$ ).

Conclusion Non adherence to ATS/ERS lung function testing guidance at work can cause the $\mathrm{FEV}_{1}$ and FVC to be underestimated by clinically significant amounts.

\section{P253 COULD APPLICATION OF SIMPLE DIAGNOSTIC ALGORITHM AID ONWARD REFERRAL FOR OPTIMISATION OF PRE-EXISTING CONDITIONS IN PATIENTS BEING CONSIDERED FOR MAJOR SURGERY?}

1J Hornsby, ${ }^{1} \mathrm{P}$ Higgins, ${ }^{2} \mathrm{~A}$ Baker, ${ }^{2} \mathrm{E}$ Black, ${ }^{2} \mathrm{D}$ Anderson. ${ }^{1}$ Queen Elizabeth University Hospital, Glasgow, UK; ${ }^{2}$ Victoria Infirmary, Glasgow, UK

\subsection{6/thoraxjnl-2016-209333.396}

Introduction Cardiopulmonary exercise testing (CPET) is used to identify physiological limitation to exercise and aid diagnosis of cardiorespiratory, psychological and muscle disorders. ${ }^{1}$ It is also frequently used to stratify operative risk thereby aiding decision making in patients considered for major surgical procedures. ${ }^{2}$ 